\title{
Real Time Simulation of Power Electronics Medium Voltage DC-Grid Simulator
}

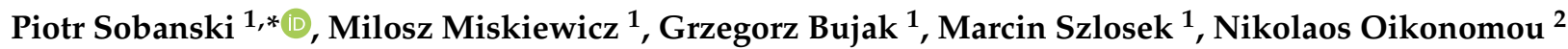 \\ and Kai Pietilaeinen ${ }^{2, *}$ \\ 1 ABB Corporate Technology Center, Starowislna 13A, 31-038 Cracow, Poland; \\ milosz.miskiewicz@pl.abb.com (M.M.); grzegorz.bujak@pl.abb.com (G.B.); marcin.szlosek@pl.abb.com (M.S.) \\ 2 ABB Medium Voltage Drives, 5300 Turgi, Switzerland; nikolaos.oikonomou@ch.abb.com \\ * Correspondence: piotr.sobanski@pl.abb.com (P.S.); kai.pietilaeinen@ch.abb.com (K.P.)
}

check for updates

Citation: Sobanski, P.; Miskiewicz, M.; Bujak, G.; Szlosek, M.;

Oikonomou, N.; Pietilaeinen, K. Real Time Simulation of Power Electronics Medium Voltage DC-Grid Simulator. Energies 2021, 14, 7368. https:// doi.org/10.3390/en14217368

Academic Editors: Panos

Kotsampopoulos, Md Omar Faruque and Georg Lauss

Received: 29 September 2021

Accepted: 2 November 2021

Published: 5 November 2021

Publisher's Note: MDPI stays neutral with regard to jurisdictional claims in published maps and institutional affiliations.

Copyright: (c) 2021 by the authors. Licensee MDPI, Basel, Switzerland. This article is an open access article distributed under the terms and conditions of the Creative Commons Attribution (CC BY) license (https:// creativecommons.org/licenses/by/ $4.0 /)$.

\begin{abstract}
Power electronics medium-voltage (MV) systems must comply with the requirements defined in grid codes. These systems' compatibility with the standards can be validated by specialized testing equipment: grid simulators. This paper presents a hardware in the loop (HiL) implementation and the simulation results of a MV multiphase DC/DC converter designed for MV DC grid emulation. By using ABB's reliable, patented power converter hardware topology (US 10978948 B2) and by applying advanced control algorithms, the presented system can be used for special purposes, such as the emulation of fault events in a DC-grid used for the certification of other devices, or for other research goals. The presented concept of a power electronics DC-grid simulator (PEGS-DC) is characterized by high power capability and high voltage quality. In this paper, the general idea of a power electronics grid simulator applied for the testing of MV electrical systems is discussed. Then, details related to the PEGS-DC, such as its hardware topology and the applied modulation method are presented. Subsequently, the HiL setup is described. The main scope of this article focuses on model the description and presenting recorded HiL simulations.
\end{abstract}

Keywords: multiphase DC/DC converter; grid emulation; MV testing equipment

\section{Introduction}

The rapid development of the electric power sector, caused by renewable energy sources, active loads, and energy storage, challenges power grids, in terms of their stable and reliable operation. These systems are connected to the grid only if they meet specific requirements related to voltage quality and safe operation, as defined in standards or recommendations, e.g., in [1,2].

According to these standards, the higher harmonics of voltage and voltage THD must be limited. Furthermore, electrical systems should react in a specific manner depending on the type of grid faul events. Grid-tied systems, such as wind turbines, must remain connected under fault conditions to maintain the nominal voltage by delivering reactive power. Some grid-tied systems are allowed to operate only for a short time, due to safety reasons. For example, according to the anti-islanding protection described in IEEE Std 1547 [3], PV panels must be disconnected from the grid within $2 \mathrm{~s}$.

To address these requirements, specialized testing equipment, called grid emulators, have been developed [4]. These systems are characterized by very low voltage harmonics of a high order, and they can simulate grid fault events, such as voltage sags, frequency variation, and weak or strong grids. They can also simulate a customized grid voltage spectrum by injecting voltage harmonics.

Most converter topologies reported in the technical literature have been designed for AC grid emulation and do not have a sufficient power capability to test modern multimegawatt MV applications [5-10]. In the literature, there are two competitive solutions providing an appropriate level of voltage and power for modern MV applications [11,12]. 
Of these, the system in [11] is 15 MVA at an output voltage of $24 \mathrm{kV}$, which is obtained through a transformer $[11,13]$. The solution in [12] also uses a transformer to boost the output voltage up to the required level, i.e., over $13 \mathrm{kV}$. Its main advantage is a high overcurrent capability, i.e., $2.1 \mathrm{kA}$ per converter phase; a much more reliable topology, which does not require multiple AC/DC converters; and a very low voltage THD, which can be around $1 \%$ of the fundamental voltage, due to an LC output filter or optimal voltage pulse pattern (OPP) [14,15]. This solution employs the well-proven ACS6000 Medium Voltage drive for voltages up to $46 \mathrm{kV}$, a maximum continuous apparent power up to $20 \mathrm{MVA}$, and an emulated grid frequency in the range $0-400 \mathrm{~Hz}$ [15]. Enabling communication protocols and flexible control systems allows controlling the output voltage, to share the harmonic content of the AC grid, by adjusting the voltage frequency and amplitude. In addition, the option exists to include phases voltage asymmetry, simulate active/reactive power flows, and virtual impedances.

On the other hand, DC power grids have a good potential for future developments [16-18], and the need to test DC interfaced devices is growing. In the literature, an increasing number of different concepts of converter topologies dedicated to operation in DC-grids is observed [19-24]. Moreover, new control methods and power management strategies in microgrid systems are more frequently considered [25-29]. Typically, low or medium DC voltage systems are applied as microgrids, but for power transmission, medium or high DC voltage grids are utilized [19,24].

Contrary to the more mature AC technology, MV DC-grid simulators are still at the conceptual stage, and they are being validated as low-power prototypes [16,20,30-32]. Additionally, their voltage quality and control dynamic have not yet been fully analyzed.

The international power quality standards IEC 61000 [33] and IEEE Std1159 [1] do not make a distinction between AC and DC power systems. IEEE Std1159 describes power system electromagnetic phenomena by categorizing them into transients, short-duration root-mean-square variations (RMS), long duration RMS variations, imbalances, waveform distortions, voltage fluctuations, and power frequency variations. These phenomena are described in the context of AC networks, and in the majority of cases it is not clear how the power quality factors could be formulated for DC systems. For example the duration of oscillatory transients or voltage sags are described referring to the period of the fundamental harmonic, which does not apply to DC grids. More specific recommendations referencing MV DC-grids with a rated voltage 1-35 kV are described in IEEE Std1709 [34]. According to these recommendations the power quality is defined, referring to minimum voltage tolerance $+/-10 \%$ and maximum voltage ripples of $5 \%$ per unit.

The present article evaluates the performance of real-time simulations and of a multiphase neutral-point clamped (NPC) DC-DC converter that emulates high power MV DC grids. This converter topology is based on ABB's well-proven ACS6000 power converter with output chokes, which is a patented ABB solution [35]. It is characterized by very low output voltage ripples, a linear output voltage control characteristic, and high power output. Results of a feasibility study to use the proposed topology as a DC grid simulator by carrying out hardware-in-the-loop (HiL) experiments using the Opal-RT platform are presented.

\section{Power Electronics MV DC-Grid Simulator}

A power electronics MV DC-grid simulator is a specialized piece of equipment, which could potentially be used for the certification testing of grid-connected devices. A general system (PEGS-DC) overview is presented in Figure 1. The PEGS is connected to the AC grid through a transformer, which steps down the voltage from $13.2 \mathrm{kV}$ to $3.0 \mathrm{kV}$, which is the nominal input voltage of the applied active rectifier unit (ARU). The output voltage of the ARU (full DC-link voltage) is selected at the nominal level of $4.84 \mathrm{kV}$. This voltage can be boosted, thus extending the control range of the DC/DC converter output voltage; voltage at the point of common coupling (PCC). A multiphase buck converter is able to step down the input voltage (DC-link voltage) to the rated level of the device under testing (DUT). 
Phase chokes are required to limit the currents circulating between the phases, as well as to reduce output current ripples. Additionally, an RC filter is used to reduce output voltage ripples, which are mainly caused by the switching of the converter's thyristors.

The designed AC/DC/DC conversion system allows for bidirectional energy flow between the AC Grid and DUT, providing a wide testing capability for different types of devices that generate or consume power.

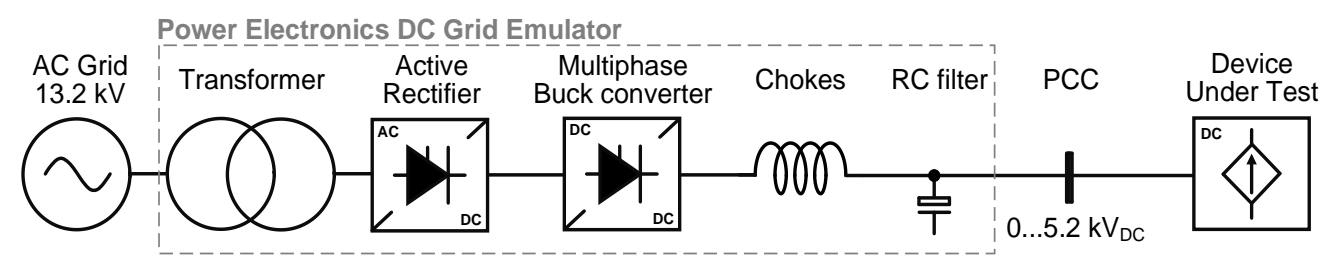

Figure 1. Simplified structure of simulated electrical system [35].

The focus of this paper is a multiphase DC/DC converter used for DC-grid emulation. Selected parts of the system are simulated using a simplified approach, which does not consider some real system behaviors, e.g., the AC grid dynamic response or the nonlinear effect of the semiconductor switching of the ARU. However, this allows for a faster model execution.

Both the active rectifier and the DC/DC converter are based on the NPC topology, which is highly reliable, but requires advanced control algorithms to obtain a high voltage quality and to balance the DC-link voltages, which is necessary for stable system operation. As mentioned before, the ARU model is simplified, but considers the following: the effect of DC/DC power converter phase voltages asymmetry, caused by nonideal switching of thyristors of the DC/DC converter; system parameter uncertainties; and dynamic load current changes to DC-link voltage.

The selected DC/DC converter topology and the parameters of the output filter unit (OFU) affect, both the dynamic performance of the system, and the output voltage quality. In the presented case, the original ABB patented solution shown in Figure 2 is used for the DC/DC conversion stage. The converter consists of six NPC legs, which produce positive or negative voltage pulses relative to the midpoint of the DC link.

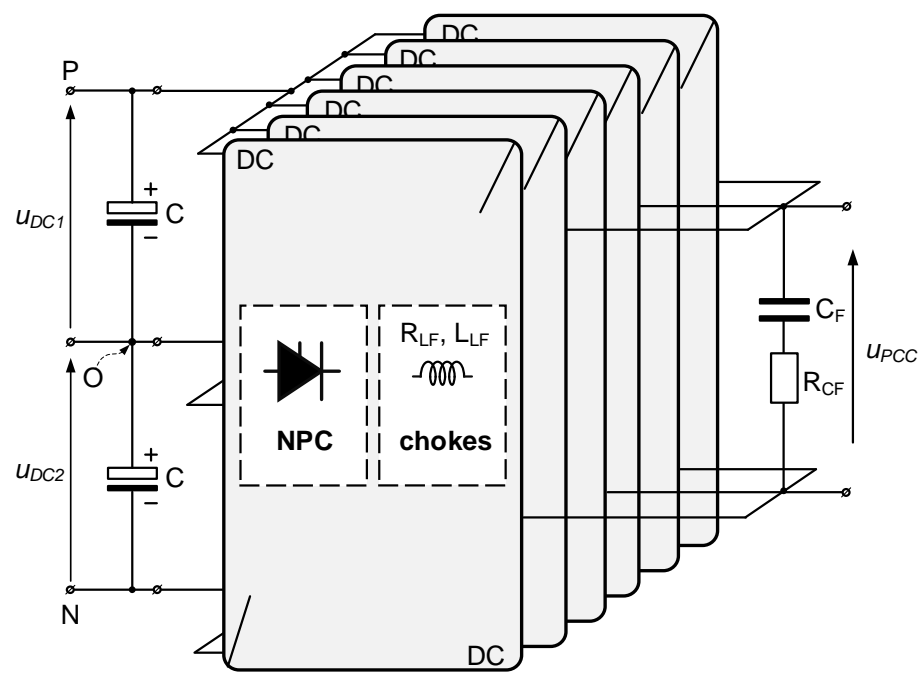

Figure 2. Six-phase DC/DC buck converter [35].

\section{DC Output Voltage Modulation}

To modulate the DC output voltage, an interleaved carrier-based PWM modulation scheme was used [36,37]. Due to the regular phase shift between carrier signals of the modulator (see Figure 3a), this technique provides very low output voltage ripples and 
high control dynamic [37]. Nevertheless, it requires implementing control algorithms to overcome issues related to the converter phase current unbalance [38] and controlling the neutral point potential of the DC-link [37]. This problem is especially important in the case of MV applications, where switching logic restrictions significantly limits the voltage modulation area. It is crucial that the HiL model is laid out so as to be able to reproduce these phenomena.

Each phase leg of the converter is controlled by comparing the carrier signals with one of the modulating waveforms, Figure 3a. At each sampling instant, one of three possible switching states $\{-1,0,+1\}$ is selected to control each of the six converter phases independently, Figure 3b. Within each phase leg, thyristors are controlled according to the classical approach known from AC applications [39], Figure 4.

\section{- modulating waveforms}

_ carrier waveforms

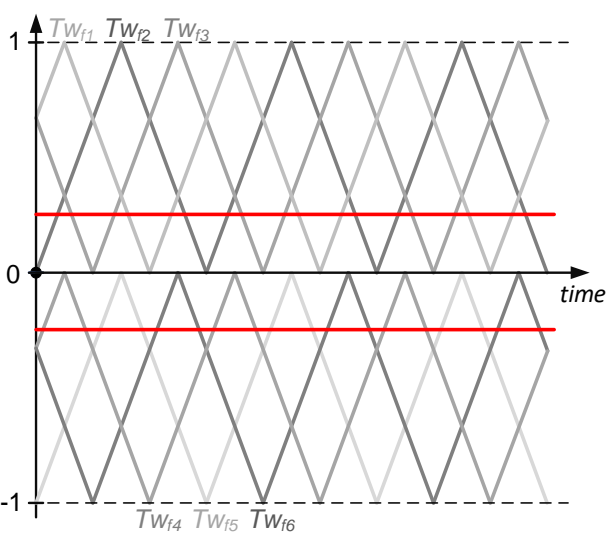

(a)
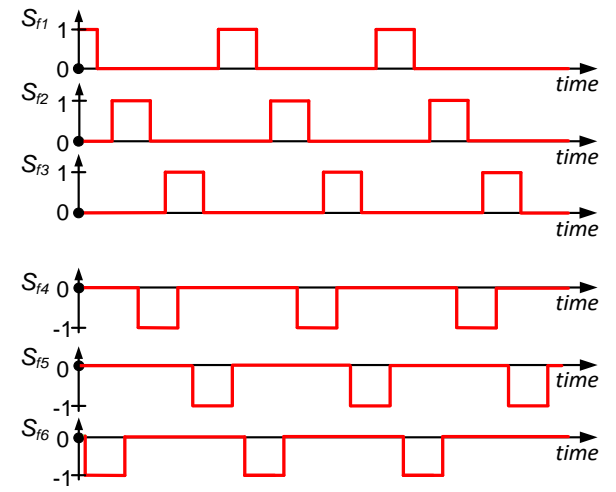

(b)

Figure 3. Modulating and carrier waveforms (a) and resulting thyristor control signals (b).
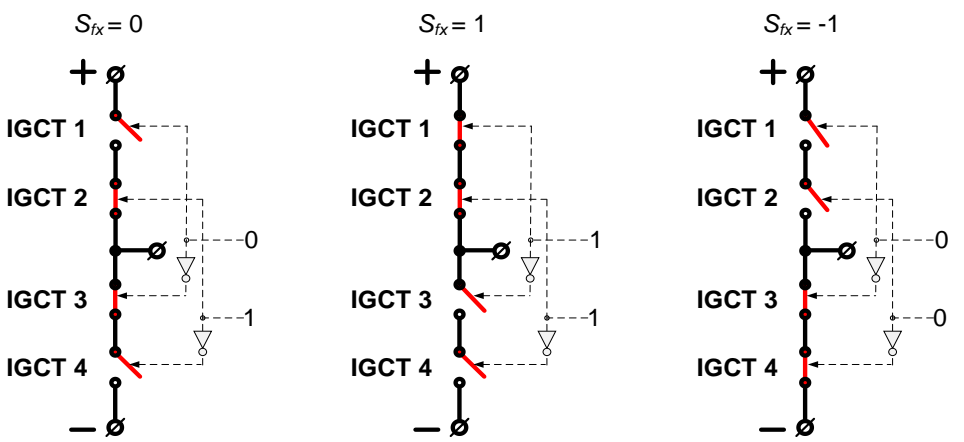

Figure 4. Thyristor control depending on switching states $S_{f x}$.

\section{HiL Setup}

The laboratory setup is presented in Figure 5. The system consists of a host computer, the main controller, the control hardware of ACS6000, and the real-time simulator. The AC800 PEC controller uses a CPU with FPGA to realize the control algorithm of choice, [40]. The CPU is used by a real-time operating system to execute, both tasks responsible for control and protections, with sampling intervals smaller than $1 \mathrm{~ms}$, and other functions, such as system configuration, which are enabled at longer sampling intervals. The FPGA is reserved for very fast control, protections, and communication, with sampling rates in the range $25 \mathrm{~ns}-25$ us. A host $\mathrm{PC}$ is used as a user interface to the HiL, allowing programing of the AC800 PEC controller and the real-time simulator, and it contains the software necessary for debugging and data acquisition. The real-time simulator is an OPAL OP5707 featuring an INTEL ${ }^{\circledR}$ CPU with eight cores and used to execute, in real-time, models 
developed in Matlab/Simulink environment with Xilinx ${ }^{\circledR}$ FPGA Virtex-7; enabling access to OP5707 I/O cards [41]. The AC800 PEC controller, OP5707 simulator, and host PC are connected to the LAN via Ethernet.

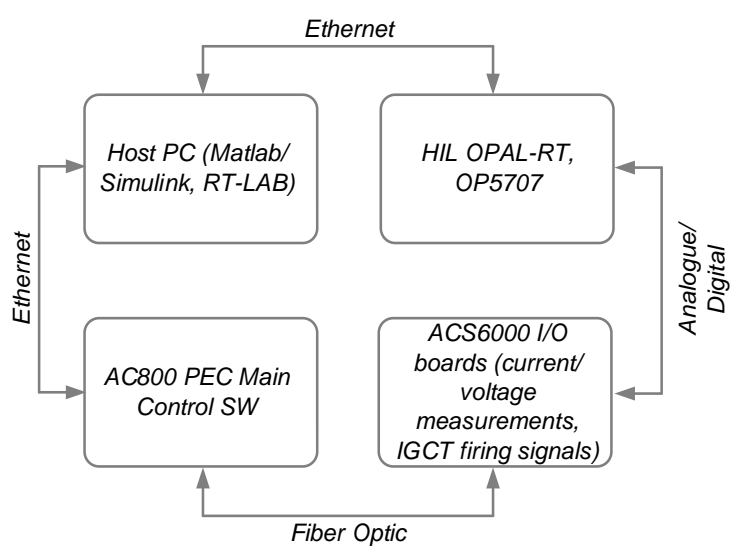

(a)

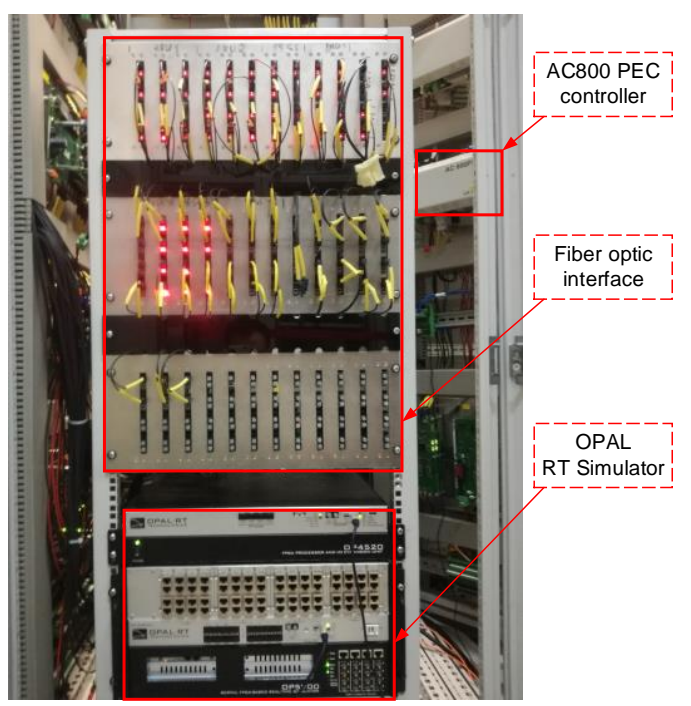

(b)

Figure 5. Simplified diagram (a), and laboratory HiL setup view (b).

The Ethernet connection is used by the host PC to upload firmware, monitor signals, and debug both the controller and real-time simulator. A fiber optics connection between the ACS800 PEC and ACS6000 control hardware permits real-time digital communication, which is used by the main controller to transfer thyristor switching commands and receive measurements from the ACS6000. Finally, the thyristor switching signals undergo opticalto-electrical conversion and are read by the OP5707, which in turn generates feedback signals to establish closed-loop control.

\section{HiL Plant Model}

\subsection{Model of the Active Rectifier}

The active rectifier controls the DC link voltage and simultaneously compensates the reactive power. By applying PWM to control the power semiconductors, the input currents are shaped to be as sinusoidal as possible, with a low content of higher harmonics. The detailed HiL implementation of the ARU vector control is not crucial, considering that the main purpose of this paper is to simulate the DC/DC converter. Additionally, it is important to reduce the computational effort related to the model execution, so as to run it with the highest possible sampling frequency, which improves accuracy.

Thus, the ARU model was simplified to a system consisting of two capacitors and a PI controller of the full DC-link voltage; the PI controller includes an anti-windup feature. This approach allows simulating the DC-link voltage unbalances and voltage excursions caused by rapid load current changes.

In Figure 6, a model of the active rectifier is presented. DC-link voltage values were calculated based on a model designed in the standard Simulink library. Since the SimPower System library was used to model the DC/DC converter, additional SimPower System blocks, representing controllable voltage sources, were applied. 


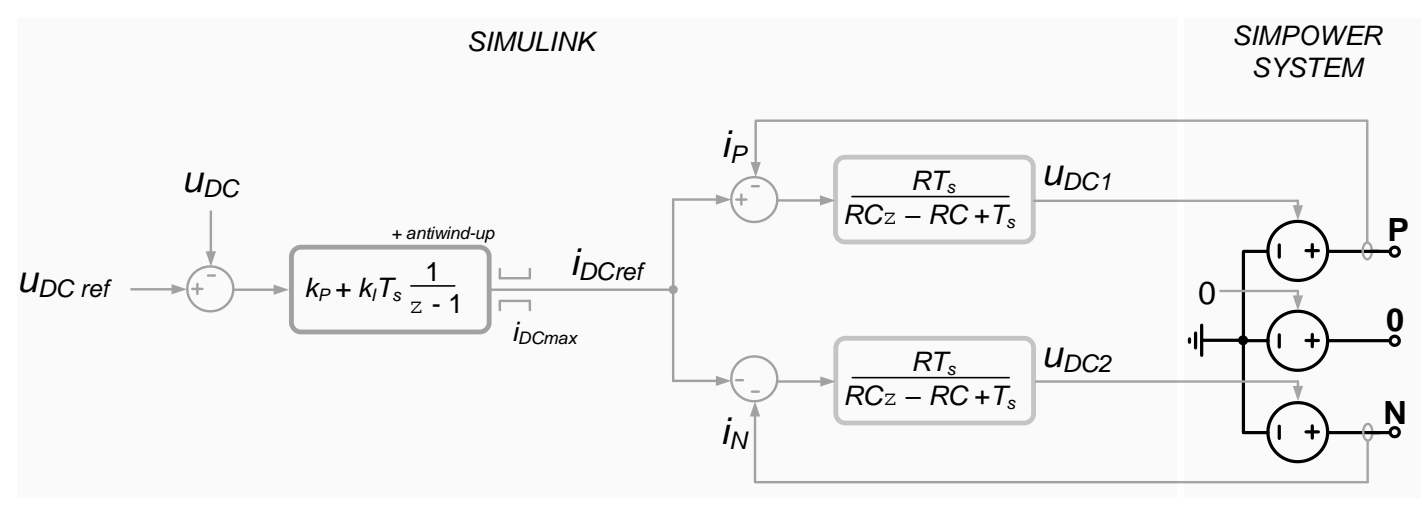

Figure 6. Model of the active rectifier.

Abbreviations and symbols used in Figure 6 are explained in Table 1.

Table 1. Abbreviations and symbols used to describe the ARU model.

\begin{tabular}{|c|c|c|}
\hline $\begin{array}{c}\text { Abbreviation/ } \\
\text { Symbol }\end{array}$ & Value & Description \\
\hline$u_{D C}$ ref & $4.84 \mathrm{kV}$ & reference ARU voltage \\
\hline$u_{D C}$ & - & measured ARU voltage \\
\hline$i_{D C \text { ref }}$ & - & reference DC-link current \\
\hline$i_{D C \max }$ & $12 \mathrm{kA}$ & PI controller output signal limitation \\
\hline$i_{P}$ & - & positive terminal current \\
\hline$i_{N}$ & - & negative terminal current \\
\hline$u_{D C 1}$ & - & DC-link positive voltage (referred to midpoint of capacitors) \\
\hline$u_{D C 2}$ & - & DC-link negative voltage (absolute value referred to midpoint of capacitors) \\
\hline$k_{P}$ & 0.625 & proportional gain of voltage controller \\
\hline$k_{I}$ & $5.5 \times 10^{-3}$ & integral gain of voltage controller \\
\hline C & $28.8 \mathrm{mF}$ & capacitance of half of DC-link capacitor bank \\
\hline$R$ & $200 \mathrm{k} \Omega$ & resistance of resistor connected parallel to half of DC-link capacitors (paralleling resistor) \\
\hline Ts & $25 \mu \mathrm{s}$ & model sampling time \\
\hline
\end{tabular}

\subsection{Model of 6-Phase DC/DC Step-Down Converter}

The DC/DC converter was modelled using specialized toolboxes in Matlab/Simulink and OPAL-RT, dedicated to the modelling of electrical circuits and power electronics converters. The buck converter, which is connected to the ARU, is represented by controllable voltage sources, Figure 6 . The reference voltages are calculated according to the mathematical model realized in Simulink. For the calculation of this model, measurements of the DC-link currents are required. A six-phase DC/DC power electronics converter was modelled using OPAL-RT blocks "TSB3_hiZR1". They are controlled according to gate control signals provided by the ACS800 PEC. They are read by the dedicated blocks "TSBIn" of OPAL-RT. Measurements of currents and voltages were realized using Matlab SimPower System, Figure 7. The same library was used to design the remaining part of the electrical circuit model (see parameters in Table 2).

Table 2. Electrical circuit parameters.

\begin{tabular}{ccc}
\hline Symbol & Value & Description \\
\hline$L_{F}$ & $2 \mathrm{mH}$ & inductance of phase choke \\
$R_{L F}$ & $20 \mathrm{~m} \Omega$ & choke phase resistance \\
$C_{F}$ & $1.4 \mathrm{mF}$ & capacitance of output RC filter \\
$R_{C F}$ & $0.5 \Omega$ & resistance of output RC filter \\
$T s$ & $25 \mu \mathrm{s}$ & model sampling time \\
\hline
\end{tabular}




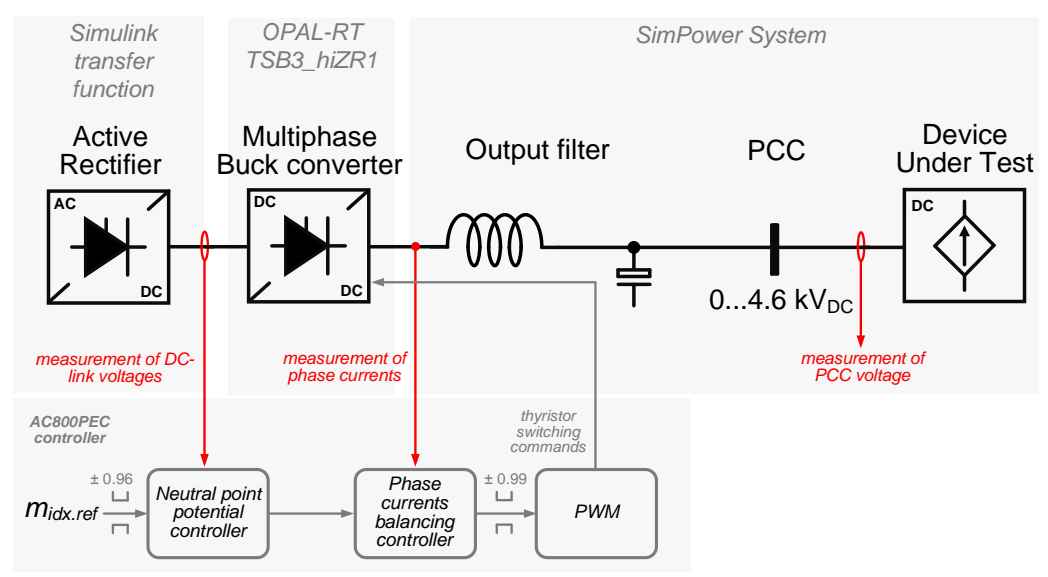

Figure 7. Model of DC/DC multiphase converter with a simplified control structure.

The DUT was modelled as a standard controllable current source available in SimPower System. The "OPTrigger" function is used to store the results. Some measurements are sent via an analog output to the AC800 PEC to be used for control. For this purpose, "OPFcnCommonAnalogOut" was utilized.

\section{HiL Simulation Results}

In this chapter, the HiL-simulation results are presented, to show the performance of the modelled system. First, the static characteristics are shown. Then, the output voltage is described in the frequency domain. After that, the dynamic system response is evaluated. Finally, selected issues related to the converter topology are explained.

\subsection{Static Characteristics}

In Figure 8a, an average value of the PCC voltage, depending on the voltage modulation index is presented. The obtained characteristic is linear, except at the boundaries of the control range, where switching logic restrictions influence the voltage control margins, because of the reduced width of the generated voltage pulses. In Figure 8b, a characteristic of the relative error of the voltage modulation, referring to the expected voltage, is presented. In the voltage range $0.5-4.5 \mathrm{kV}$, these error values are below $0.5 \%$, complying with the requirements of IEEE Std1709.

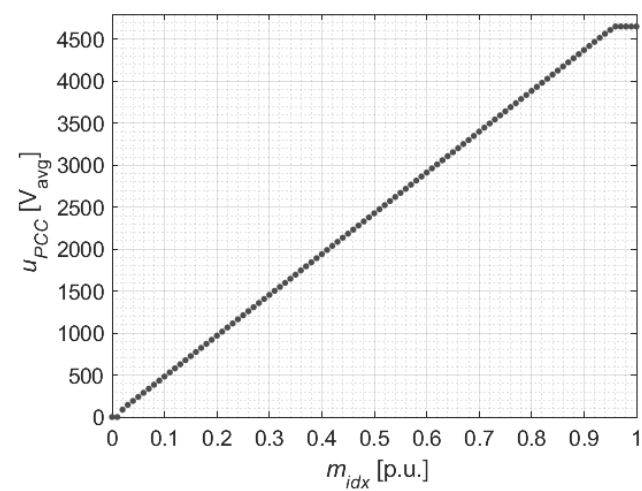

(a)

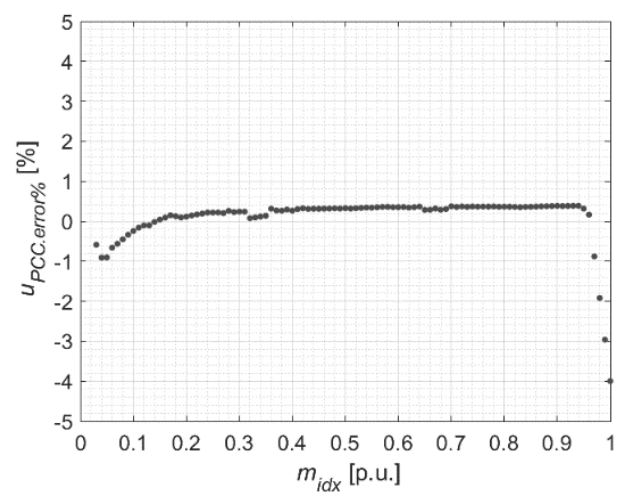

(b)

Figure 8. Characteristics of voltage control (a), relative error of the voltage modulation (b).

One of the most important factors that determines if the converter can be used as a DC-grid emulator is the level of voltage oscillations, which mainly originate from the switching frequency of the thyristors or from the DC-link voltage fluctuations, i.e., ARU voltage oscillations. In Figure 9, a static characteristic of peak-to-peak PCC voltage ripples is shown. Similarly, the root mean square (RMS) and normalized values of these ripples are 
presented in Figures 10 and 11, respectively. The normalized values of the voltage ripples were below $1 \%$ in the modulation index range $m_{i d x} \in(0.1,1)$, which is way below what is recommended in the IEEE Std1709.

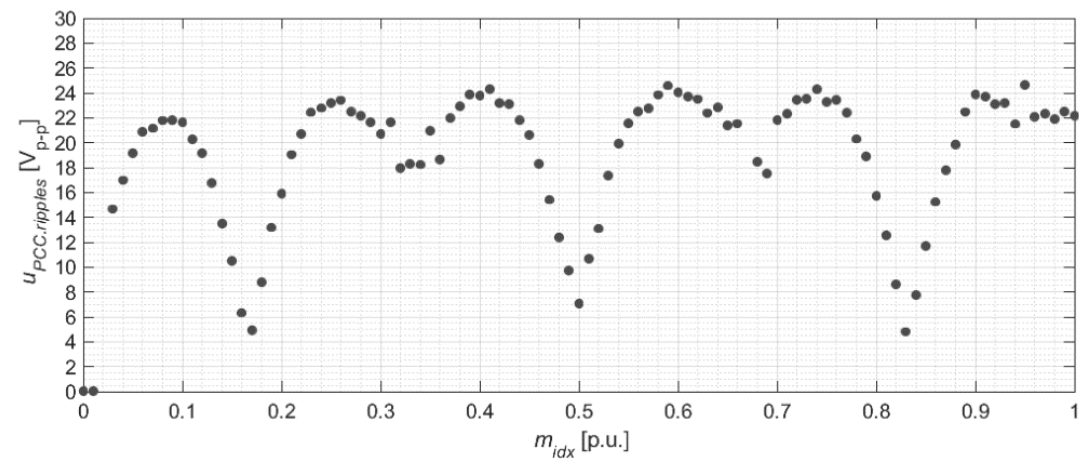

Figure 9. Peak-to-peak values of the PCC voltage ripples, depending on the modulation index.

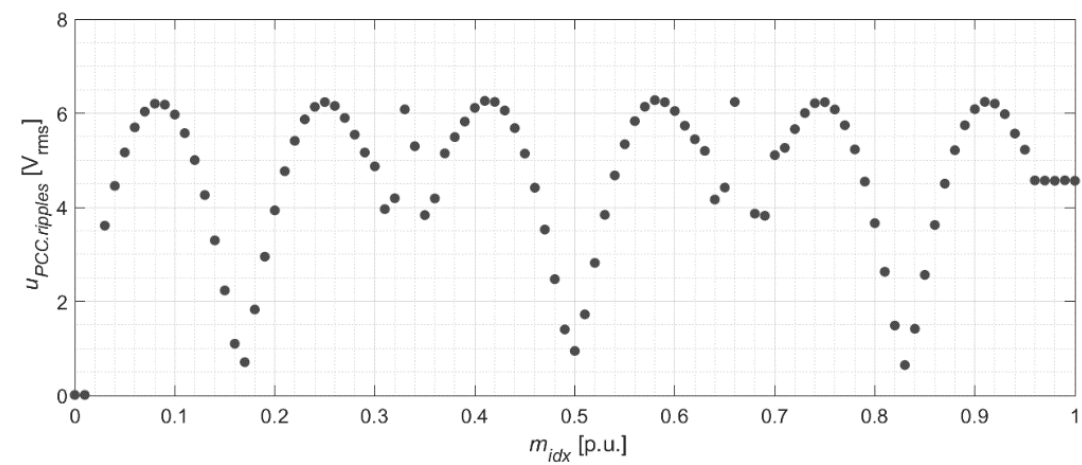

Figure 10. RMS values of the PCC voltage ripples, depending on the modulation index.

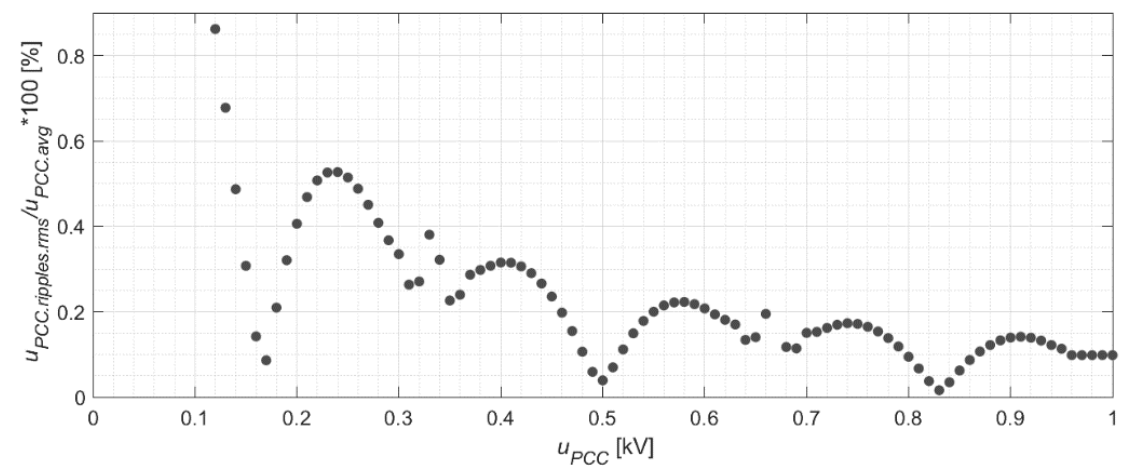

Figure 11. Normalized values of the PCC voltage ripples.

As mentioned in subchapter 2, the low amplitude of the voltage ripple is the main advantage of multiphase converters. Additionally, due to the interleaved modulation scheme, for some converter operating points, the switching ripples are fully eliminated, i.e., at $m_{i d x} \in\{1 / 6,3 / 6,5 / 6\}$. Due to the impact of the switching logic restrictions at $m_{i d x} \in\{2 / 6,4 / 6\}$, the obtained values are increased [37].

The impedance of the choke must be chosen so that the obtained current ripple, caused by the phase-to-phase voltage, does not exceed the overcurrent threshold under a steadystate, as well as during dynamic operation of the power converter. In Figure 12a, the peak-to-peak values of the phase current ripples are presented. Switching logic restrictions, which are typical for thyristor-based power electronics converters, must be compensated by the control, to avoid phase current unbalances. Nevertheless, in most cases, these algorithms lead to increased current ripples at some operating points, where the impact of 
the switching logic restrictions is the most significant, e.g., $m_{i d x} \in\{2 / 6,4 / 6\}$, as is visible in Figure 12a.

The phase currents of the power converter must be balanced to avoid overcurrent trips. Figure $12 \mathrm{~b}$ shows an example of balanced currents for the three converter phases.

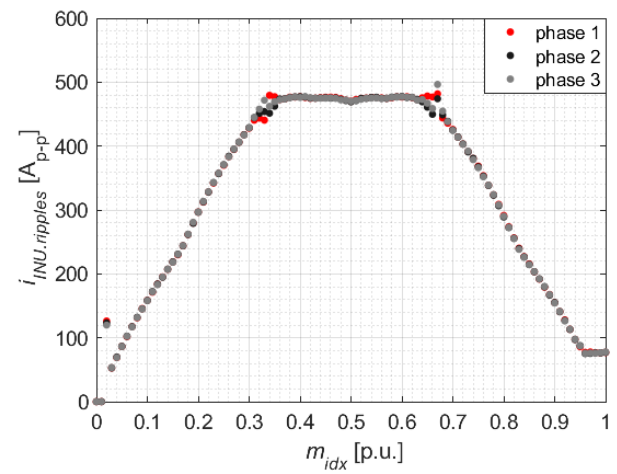

(a)

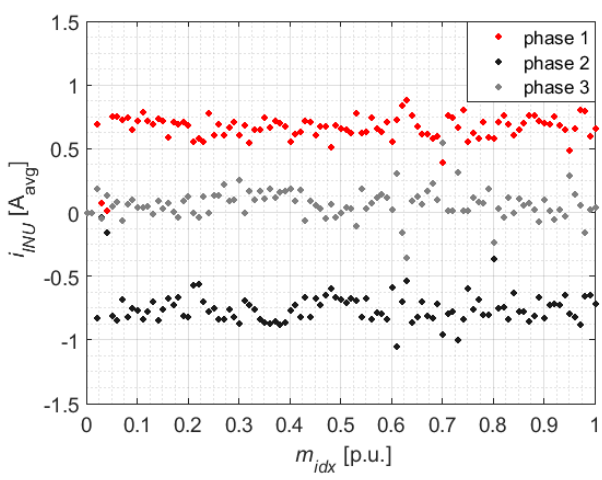

(b)

Figure 12. Phase currents ripples (a) and mean values of phase currents (b) depending on the modulation index.

A common issue related to NPC power converters is DC-link voltage unbalance [36]. Figure 13 shows the \% error of DC-link voltages relative to the nominal value of the DC-link voltage, depending on the modulation index, under converter no-load operation.

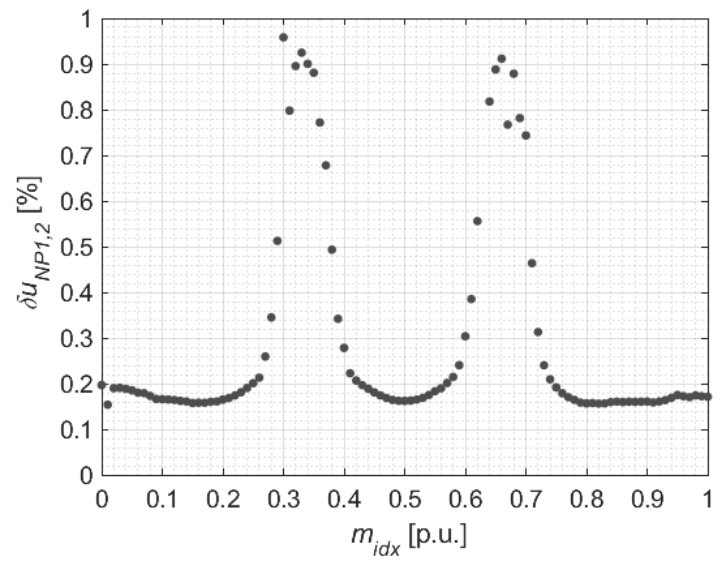

Figure 13. Relative error of the DC-link voltages in the full range of modulation index.

Switching logic restrictions cause modulation errors in the phase voltages. These errors are the highest in the range of the modulation index around $1 / 3$ and $2 / 3$. Due to this fact, the unbalancing of the DC-link voltages is around 1\% in that case. This level of error is acceptable and does not reduce the PCC voltage range and the modulation accuracy.

\subsection{Analysis in the Frequency Domain}

Since higher harmonics in the PCC voltage have a negative impact on devices connected to the grid, or can even cause microgrid system instability [42], it is important to shape accordingly the voltage spectrum of the converter, whose purpose is grid emulation. Figures 14-17 show two representative examples of voltage time-domain transients and their spectrum obtained for the designed system. In Figure 15, the dominant higher frequencies are caused by thyristors switching. Figure 17 show the spectrum of PCC voltage (Figure 16) at one of the operating points, where switching ripples are almost fully eliminated, due to the interleaved PWM scheme. 


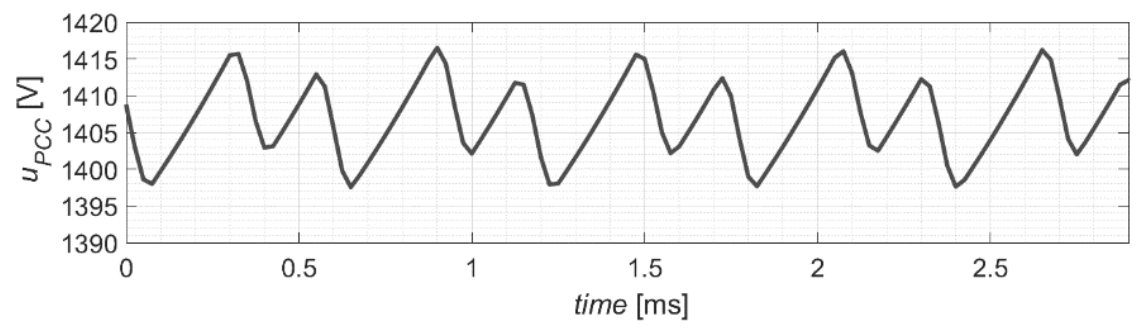

Figure 14. Time-domain transient of PCC voltage $1.4 \mathrm{kV}$.

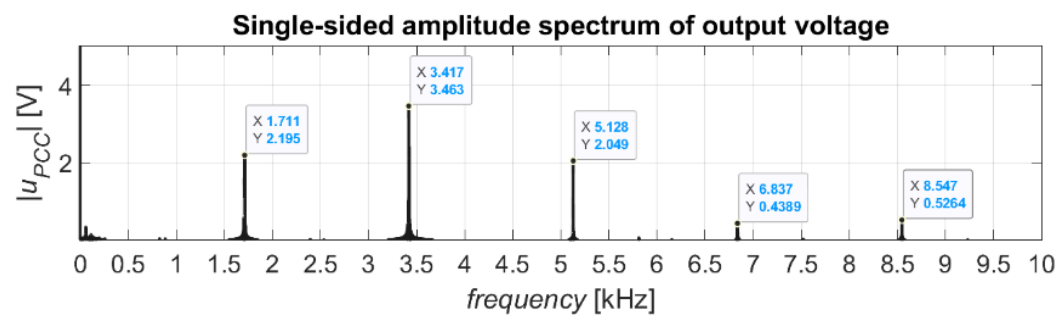

Figure 15. Spectrum of PCC voltage $1.4 \mathrm{kV}$.

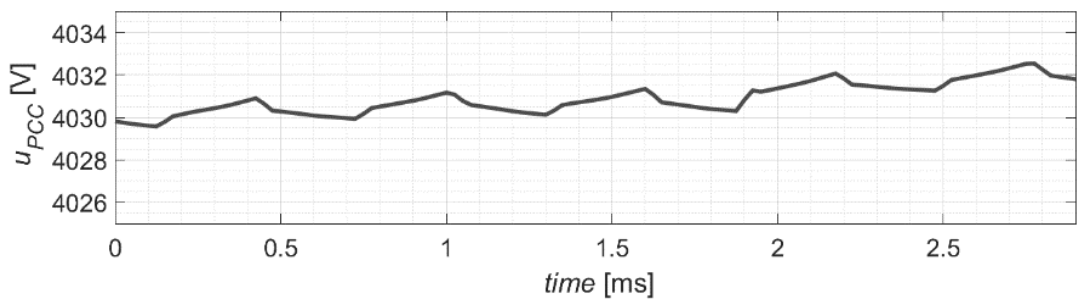

Figure 16. Time-domain transient of PCC voltage $4 \mathrm{kV}$.

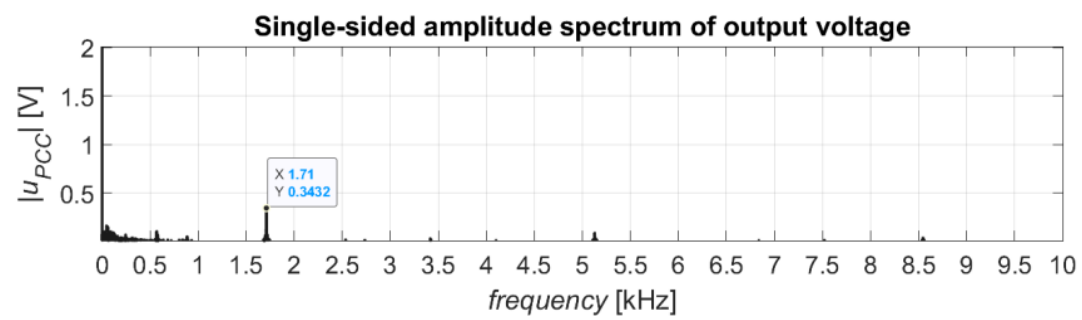

Figure 17. Spectrum of PCC voltage $4 \mathrm{kV}$.

6.3. Time-Domain Transients under Different Operating Conditions 6.3.1. Steady-State Operation

In Figure 18, a time-domain transient of the PCC voltage is shown. A very low level of voltage ripples, i.e., $18 \mathrm{~V}_{\mathrm{p}-\mathrm{p}}$, was obtained, due to the regular distribution of carrier signals of the voltage modulator and also the perfect balancing of the phase currents (Figures 19 and 20). The currents have the same amplitudes and shape, which is difficult to obtain, considering the switching logic restrictions impacting on the phase voltages in every modulation period of the DC/DC power converter. 


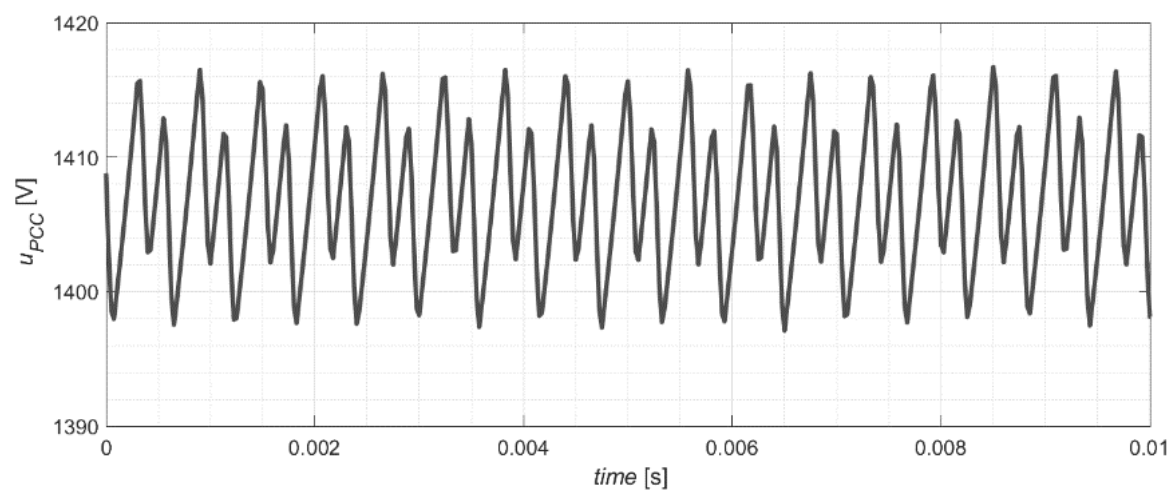

Figure 18. PCC voltage time-domain transient.

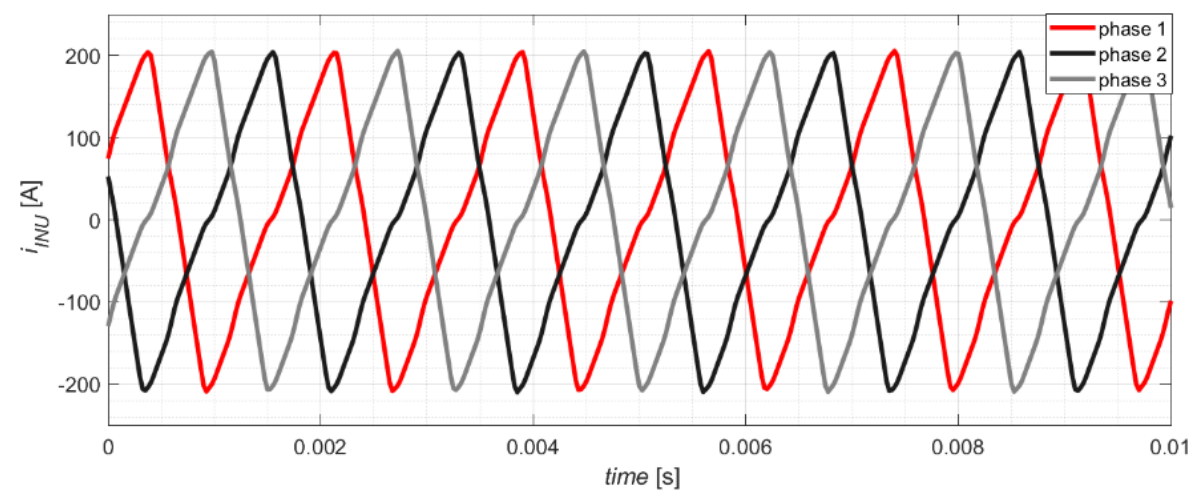

Figure 19. Converter phase (1-3) currents time-domain transients.

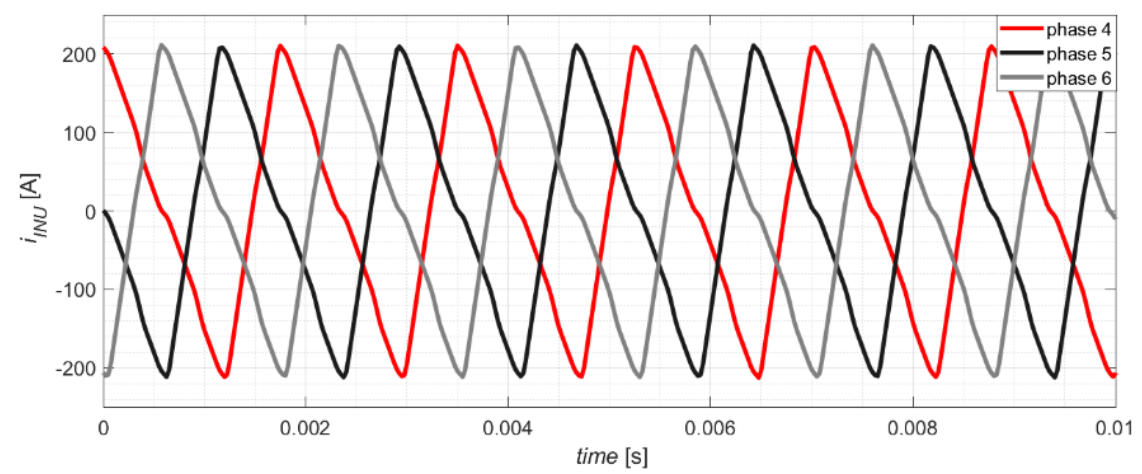

Figure 20. Converter phase (4-6) currents time-domain transients.

\subsubsection{Change of Reference Voltage Modulation Index}

To emulate various grid events, it is necessary to be able to control fast voltage changes, [43]. Figure 21 shows the transient of the PCC voltage during a step change of the modulation index. The time constant of the voltage control is mainly determined by the output circuits (chokes and RC filter). The slew rate of the reference signal must be adjusted so that a maximum acceptable voltage overshoot level is not exceeded, and so that grid connected devices are not damaged. 


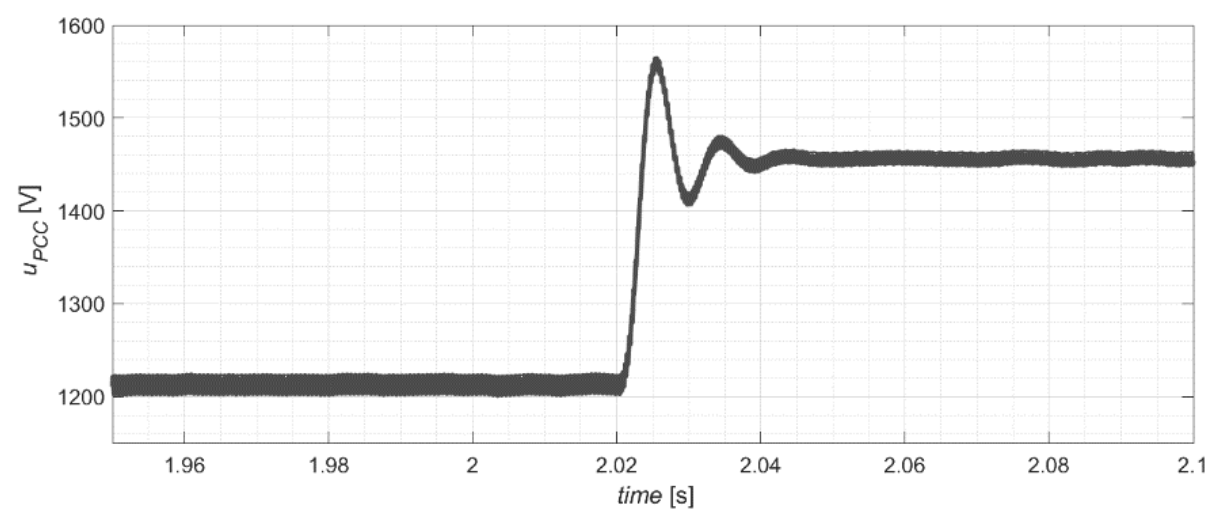

Figure 21. Step change of PCC voltage.

\subsubsection{Load Change}

For grid emulators, the most demanding test is an emergency shutdown of a device connected to the grid. Figure 22 shows the currents of the three-phase choke during a rapid change of the load current.

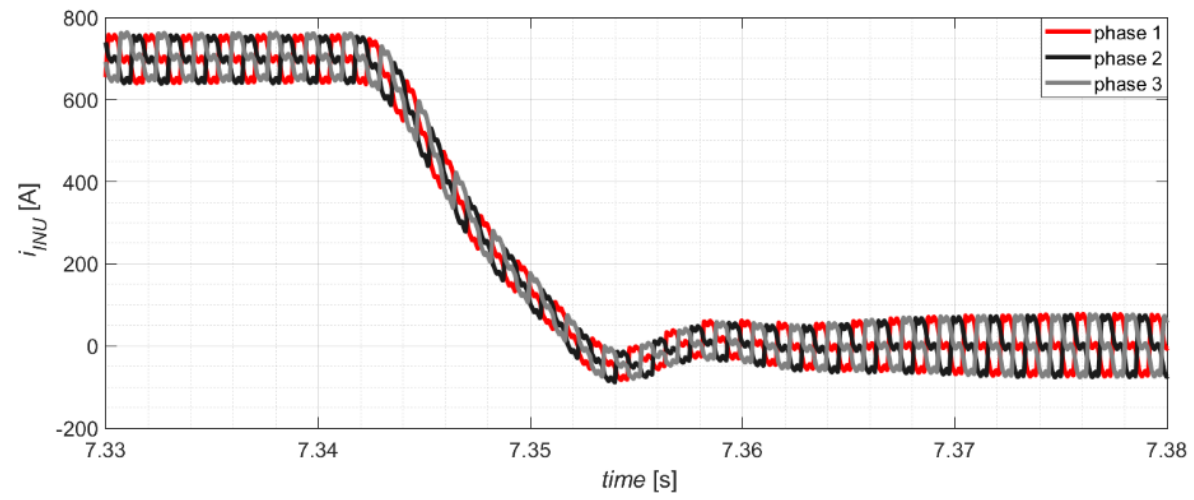

Figure 22. Three-phase converter currents during full power change $\Delta p=9.45 \mathrm{MW}$ at converter voltage $4.5 \mathrm{kV}$.

From the grid emulation perspective, the most important aspect is to avoid a converter trip due to overvoltage of the DC-link and also to avoid a high transient of the current, which was obtained in the presented system.

\subsection{Multiphase DC/DC Converter Control Issues}

As mentioned in the introduction to this chapter, there are some issues related to the multiphase DC/DC converter topology, making its control relatively complex. The most important of those issues are related to system parameter uncertainty and switching logic restrictions. In Figure 23, the converter phase currents are shown during voltage modulation in the range that is highly affected by switching logic. It is visible that the currents are permanently unbalanced due to the phase voltage modulation error. Owing to this, the margin to the overcurrent threshold is lower, and there is a risk of converter trip during dynamic states, e.g., a rapid change of DUT current. For this reason, it is important to design an appropriate control to ensure balanced currents [38]. In the presented example, the phase current controller was enabled at the time instant $23.2 \mathrm{~s}$, equalizing the DCcomponent of the currents.

To provide a stable system operation, NPC power converters require the balancing of the DC-link voltage. A respective model of the active rectifier is needed. Figure 24 shows the DC-link voltages during converter operation with a disabled function to balance the DC-link voltages; the difference between these voltages is increased, which can result in tripping the converter. At the time instant $20.7 \mathrm{~s}$, a controller of neutral point potential of 
the DC-link was activated. Then, in $0.2 \mathrm{~s}$ the DC-link voltages were balanced to the level defined by the controller's hysteresis. This hysteresis is equal to $40 \mathrm{~V}$ and must be higher than the expected DC-link voltage ripples.

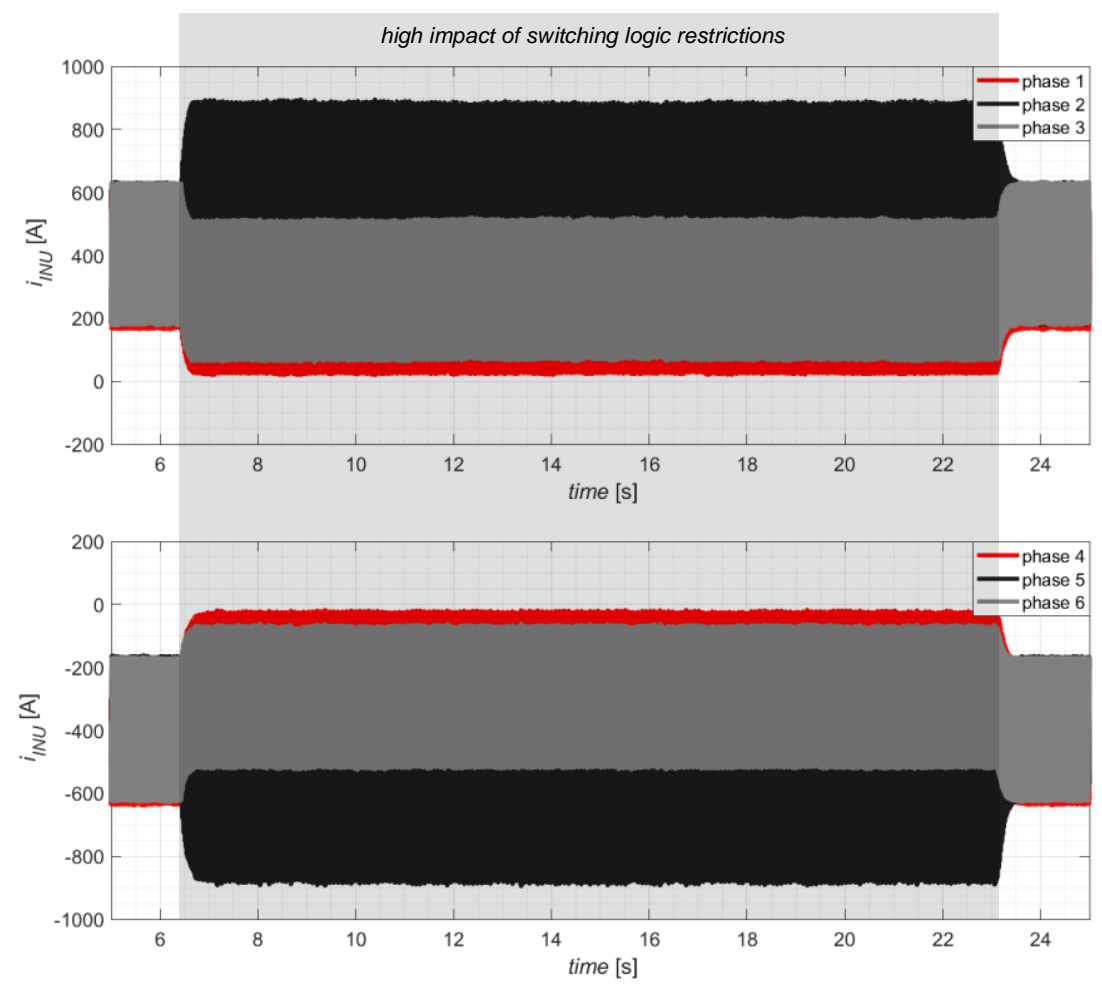

Figure 23. Converter currents in the control region significantly affected by switching logic restrictions; current balancing algorithm was disabled.

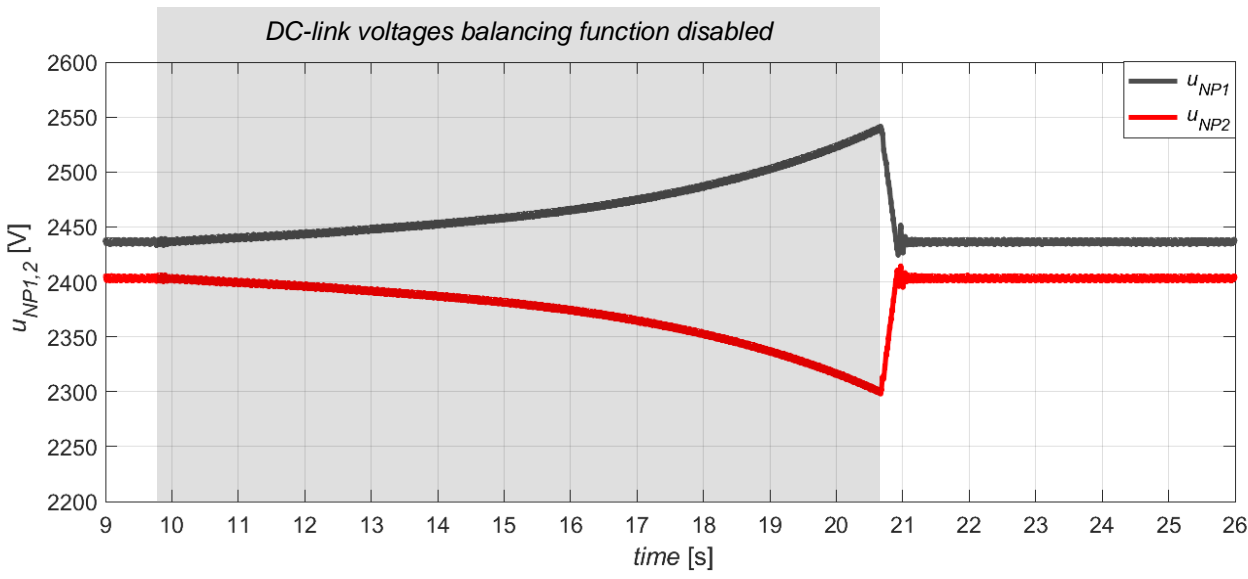

Figure 24. DC-link voltages when the controller neutral point potential of the DC-link is temporarily disabled.

\section{Discussion}

In this paper, the concept of a power electronics DC-grid simulator, designed to test medium voltage DC-grid-connected devices, such as PV panels, storage systems, and DC/AC converters used for general purposes, was presented. To emulate the DC-grid, a controllable DC-voltage source was designed. It allowed simulating the bidirectional energy flow between tested devices and the main electrical system. The main investigation was related to the control validation and performance evaluation of the DC/DC multiphase converter. 
The presented approach of HiL simulations assumes a plant model optimization in terms of complexity; contrary to the DC/DC converter, whose detailed simulation was the main purpose of this study, the active rectifier was modelled in a simplified manner. At the same time, all the important issues observed in a real system, such as DC-link voltage imbalance or phase current imbalance, were modelled. As a result, a plant model could be executed with the relatively short sampling interval time of 25 us, which increases the accuracy of calculations. Selected system variables could be sent via digital outputs of the OPAL to a PC with the same resolution and stored in a file. Additionally, some signals, such as the DC-link voltages and the converter phase currents, could be read by the PEC, using the analog outputs of the OPAL. This allows for control of the power converter, which is modelled in real time, using the industrial controller AC800 PEC.

The obtained results were analyzed in the context of voltage quality and control reliability under a converter steady-state operation, as well as during demanding transients. According to IEEE Std1709, PEGS can be used to certify MV DC grid-connected devices.

Author Contributions: Conceptualization, P.S. and G.B.; methodology, P.S., G.B.; software, P.S. and G.B.; validation, P.S. and G.B.; formal analysis, P.S.; investigation, P.S. and G.B.; resources, M.M.; data curation, M.S.; writing—original draft preparation, P.S. and M.M.; state-of-art review, M.M. and P.S.; writing-review and editing, N.O. and K.P.; visualization, P.S.; supervision, P.S., M.M., M.S., N.O. and K.P.; project administration, M.M., M.S., N.O. and K.P.; funding acquisition, M.M., M.S., N.O. and K.P. All authors have read and agreed to the published version of the manuscript.

Funding: This research received no external funding.

Institutional Review Board Statement: Not applicable.

Informed Consent Statement: Not applicable.

Data Availability Statement: The data presented in this study are available on request from the corresponding author.

Conflicts of Interest: The authors declare no conflict of interest.

\section{References}

1. IEEE Recommended Practice for Monitoring Electric Power Quality; IEEE Std 1159TM-2019; IEEE: Piscataway, NJ, USA, 2019.

2. Wind Energy Generation Systems-Part 21-1: Measurement and Assessment of Electrical Characteristics-Wind Turbines 2019; IEC 61400-211; IEC: Geneva, Switzerland, 2019.

3. IEEE Standard Conformance Test Procedures for Equipment Interconnecting Distributed Energy Resources with Electric Power Systems and Associated Interfaces-Redline 2020; IEEE Std 1547.1; IEEE: Piscataway, NJ, USA, 2020.

4. Ma, K.; Wang, J.; Cai, X.; Blaabjerg, F. AC Grid Emulations for Advanced Testing of Grid-Connected Converters-An Overview. IEEE Trans. Power Electron. 2021, 36, 1626-1645. [CrossRef]

5. Schmitt, A.; Gommeringer, M.; Kolb, J.; Braun, M. A high current, high frequency modular multiphase multilevel converter for power hardware-in-the-loop emulation. In Proceedings of the International Exhibition and Conference for Power Electronics, Intelligent Motion, Renewable Energy and Energy Management (PCIM), Nuremberg, Germany, 20-22 May 2014; pp. 1-8.

6. Mentesidi, K.; Rikos, E.; Kleftakis, V.; Kotsampopoulos, P.; Santamaria, M.; Aguado, M. Implementation of a Microgrid Model for DER Integration in Real-Time Simulation Platform. In Proceedings of the 2014 IEEE 23rd International Symposium on Industrial Electronics (ISIE), Istambul, Turkey, 1-4 June 2014; pp. 2274-2279. [CrossRef]

7. Kotsampopoulos, P.C.; Kleftakis, V.A.; Hatziargyriou, N.D. Laboratory Education of Modern Power Systems Using PHIL Simulation. IEEE Trans. Power Syst. 2017, 32, 3992-4001. [CrossRef]

8. Mao, C.; Feng, L.; Junlin, L.; Shuoting, Z.; Lidong, Z.; Ran, M.; Dan, W.; Jie, Z.; Xun, C.; Ranran, A.; et al. A 400-V/50-kVA Digital-Physical Hybrid Real-Time Simulation Platform for Power Systems. Trans. Ind. Electron. 2018, 65, 3666-3676. [CrossRef]

9. Si, G.; Cordier, J.; Kennel, R.M. Extending the Power Capability With Dynamic Performance of a Power-Hardware-in-the-Loop Application-Power Grid Emulator Using “Inverter Cumulation”. Trans. Ind. Appl. 2016, 52, 3193-3202. [CrossRef]

10. Lasseter, R.H.; Eto, J.H.; Schenkman, B.; Stevens, J.; Vollkommer, H.; Klapp, D.; Linton, E.; Hurtado, H.; Roy, J. CERTS Microgrid Laboratory Test Bed. Trans. Power Deliv. 2011, 26, 325-332. [CrossRef]

11. Ledezma, E.; Wang, K.; Keister, T.; Edwards, R.; Pipho, R.; Palle, B.; Kulkarni, D.; Salem, T.E.; Fox, J.C.; Parsa, L. Development of a modular configurable multi-megawatt power amplifier. In Proceedings of the Annual Conference of the IEEE Industrial Electronics Society (IECON), Viena, Austria, 10-13 November 2013; pp. 631-636. [CrossRef] 
12. Koralewicz, P.; Gevorgian, V.; Wallen, R.; van der Merwe, W.; Jörg, P. Advanced grid simulator for multi-megawatt power converter testing and certification. In Proceedings of the IEEE Energy Conversion Congress and Exposition (ECCE), Milwaukee, WI, USA, 18-22 September 2016; pp. 1-8. [CrossRef]

13. Fox, J.C.; Gislason, B. Introduction to the Clemson university $15 \mathrm{MW}$ hardware-in-the-loop grid simulator. In Proceedings of the Clemson University Power Systems Conference, Clemenson, CM, USA, 11-14 March 2014; pp. 1-5. [CrossRef]

14. Geyer, T.; Oikonomou, N.; Papafotiou, G.; Kieferndorf, F.D. Model Predictive Pulse Pattern Control. Trans. Ind. Appl. 2012, 48, 663-676. [CrossRef]

15. Miskiewicz, M.; Chekavskyy, G.; Sobanski, P.; Bujak, G.; Szlosek, M.; Oikonomou, N.; Halbeis, M.; Pietilaeinen, K.; Eckerle, J.; Galang, J.; et al. ABB's ACS6000 Power Electronics Grid Simulator, PEGS, Tests Medium Voltage Equipment; ABB Review 2020; ABB: Zürich, Switzerland, 2020; pp. 52-57.

16. Lakshmi, M.; Hemamalini, S. Nonisolated High Gain DC-DC Converter for DC Microgrids. Trans. Ind. Electron. 2018, 65, 1205-1212. [CrossRef]

17. Yuan, C.; Haj-ahmed, M.A.; Illindala, M.S. Protection Strategies for Medium-Voltage Direct-Current Microgrid at a Remote Area Mine Site. Tran. Ind. Appl. 2015, 51, 2846-2853. [CrossRef]

18. Flourentzou, N.; Agelidis, V.G.; Demetriades, G.D. VSC-Based HVDC Power Transmission Systems: An Overview. Trans. Power Electron. 2009, 24, 592-602. [CrossRef]

19. Engel, S.P.; Stieneker, M.; Soltau, N.; Rabiee, S.; Stagge, H.; De Doncker, R.W. Comparison of the Modular Multilevel DC Converter and the Dual-Active Bridge Converter for Power Conversion in HVDC and MVDC Grids. Trans. Power Electron. 2015, 30, 124-137. [CrossRef]

20. Kenzelmann, S.; Rufer, A.; Dujic, D.; Canales, F.; de Novaes, Y.R. A versatile DC/DC converter based on modular multilevel converter for energy collection and distribution. In Proceedings of the IET Conference on Renewable Power Generation (RPG), Edinburgh, UK, 6-8 September 2011; pp. 1-6. [CrossRef]

21. Montesinos-Miracle, D.; Massot-Campos, M.; Bergas-Jane, J.; Galceran-Arellano, S.; Rufer, A. Design and Control of a Modular Multilevel DC/DC Converter for Regenerative Applications. Trans. Power Electron. 2013, 28, 3970-3979. [CrossRef]

22. Fan, H.; Li, H. High-Frequency Transformer Isolated Bidirectional DC-DC Converter Modules with High Efficiency Over Wide Load Range for 20 kVA Solid-State Transformer. Trans. Power Electron. 2011, 26, 3599-3608. [CrossRef]

23. Zheng, Z.; Han, X.; An, Z.; Kandula, P.R.; Kandasmy, K.; Saeedifard, M.; Divan, D. SiC-Based 5-kV Universal Modular SoftSwitching Solid-State Transformer (M-S4T) for Medium-Voltage DC Microgrids and Distribution Grids. Trans. Power Electron. 2021, 36, 11326-11343. [CrossRef]

24. Hannan, M.A.; Hussin, I.; Ker, P.J.; Hoque, M.M.; Hossain Lipu, M.S.; Hussain, A.; Rahman, M.S.A.; Faizal, C.W.M.; Blaabjerg., F. Advanced Control Strategies of VSC Based HVDC Transmission System: Issues and Potential Recommendations. IEEE Access 2018, 6, 78352-78369. [CrossRef]

25. Nougain, V.; Panigrahi, B.K. An Integrated Power Management Strategy of Grid-Tied DC Microgrid including Distributed Energy Resources. Trans. Ind. Inform. 2020, 16, 5180-5190. [CrossRef]

26. Kirtane, P.S.; Shendge, A.D. Control and Management of Autonomous Power between Standalone DC Microgrids. In Proceedings of the International Conference on Communication and Electronics Systems (ICCES), Coimbatore, India, 17-19 July 2019; pp. 1811-1815. [CrossRef]

27. Ma, T.; Cintuglu, M.H.; Mohammed, O.A. Control of a Hybrid AC/DC Microgrid Involving Energy Storage and Pulsed Loads. Trans. Ind. Appl. 2017, 53, 567-575. [CrossRef]

28. Dragičević, T.; Lu, X.; Vasquez, J.C.; Guerrero, J.M. DC Microgrids-Part I: A Review of Control Strategies and Stabilization Techniques. Trans. Power Electron. 2016, 31, 4876-4891. [CrossRef]

29. Nasirian, V.; Moayedi, S.; Davoudi, A.; Lewis, F.L. Distributed Cooperative Control of DC Microgrids. Trans. Power Electron. 2015, 30, 2288-2303. [CrossRef]

30. Debnath, S.; Zheng, S.; Watson, N.; Campbell, S.; Zeng, R.; Chinthavali, M. Flexible Intelligent Real-Time DC-AC Grid Emulator (FIRE): Power Electronic Hardware-in-the-Loop (PE-HIL) Amplifier; Energy Conversion Congress and Exposition (ECCE): Baltimore, MD, USA, 2019; pp. 1060-1067. [CrossRef]

31. Li, Y.; Shi, X.; Liu, B.; Lei, W.; Wang, F.; Tolbert, L.M. Development, Demonstration, and Control of a Testbed for Multiterminal HVDC System. Trans. Power Electron. 2017, 32, 6069-6078. [CrossRef]

32. Ryu, M.; Kim, H.; Baek, J.; Kim, H.; Jung, J. Effective Test Bed of 380-V DC Distribution System Using Isolated Power Converters. IEEE Trans. Ind. Electron. 2015, 62, 4525-4536. [CrossRef]

33. Electromagnetic Compatibility (EMC)-Part 4-30: Testing and Measurement Techniques-Power Quality Measurement Methods 2021; IEC 61000-4-30; IEC: Geneva, Switzerland, 2021.

34. IEEE Recommended Practice for $1 \mathrm{kV}$ to $35 \mathrm{kV}$ Medium-Voltage DC Power Systems on Ships 2018; IEEE Std 1709-2018; IEEE: Piscataway, NJ, USA, 2018. [CrossRef]

35. Du, Y.; Aeloiza, E.; Burgos, R. Interleaved Multi-Channel, Multi-Level, Multi-Quadrant DC-DC Converters. U.S. Patent 10978948 B2, 13 April 2021.

36. Grbović, P.J.; Delarue, P.; Le Moigne, P.; Bartholomeus, P. A Bidirectional Three-Level DC-DC Converter for the Ultracapacitor Applications. Trans. Ind. Electron. 2010, 57, 3415-3430. [CrossRef] 
37. Drobnic, K.; Grandi, G.; Hammami, M.; Mandrioli, R.; Ricco, M.; Viatkin, A.; Vujacic, M. An Output Ripple-Free Fast Charger for Electric Vehicles Based on Grid-Tied Modular Three-Phase Interleaved Converters. Trans. Ind. Appl. 2019, 55, 6102-6114. [CrossRef]

38. Oraw, B.; Ayyanar, R. Multivariable analysis of VR controllers with load line regulation and phase current balancing. In Proceedings of the Applied Power Electronics Conference and Exposition (APEC), Austin, TX, USA, 24-28 February 2008; pp. 1728-1734. [CrossRef]

39. Xiang, C.; Shu, C.; Han, D.; Mao, B.; Wu, X.; Yu, T. Improved Virtual Space Vector Modulation for Three-Level Neutral-PointClamped Converter with Feedback of Neutral-Point Voltage. Trans. Power Electron. 2018, 33, 5452-5464. [CrossRef]

40. Library of ABB. Available online: https://library.e.abb.com/public/a7566254919255a0c12578c3003355f7/AC\%20800PEC\%20 Sales\%20Brochure.pdf (accessed on 1 November 2021).

41. OP5700 System Description. Available online: https://wiki.opal-rt.com/display/HDGD/OP5700+System+Description (accessed on 1 November 2021).

42. Shamsi, P.; Fahimi, B. Stability Assessment of a DC Distribution Network in a Hybrid Micro-Grid Application. IEEE Trans. Smart Grid 2014, 5, 2527-2534. [CrossRef]

43. Govaerts, G.; Hallemans, L.; Driesen, J.; Martinez, W. Design of a Bipolar DC Grid Fault Emulator. In Proceedings of the 2020 5th IEEE Workshop on the Electronic Grid (eGRID), Aachen, Germany, 2-4 November 2020; pp. 1-6. [CrossRef] 